\title{
Endodontic Treatment of First Mandibular Molar in Patient who Underwent Heart Bypass Surgery: A Case Report
}

\author{
Anasia Chrisanty Sahertian and Nanik Zubaidah \\ Department of Conservative Dentistry, Faculty of Dental Medicine, Universitas Airlangga, Surabaya, Indonesia
}

\begin{abstract}
Cardiovascular disease has become increasingly common. This must serve as a motivation for dentists to be aware of the modifications of treatment and precautions in patients suffering from cardiovascular disorders. The purpose of this case is to describe endodontic treatment on the right mandibular first molar in a 65-year-old woman followed with fiber post and zirconia-based crown with a medical history of cardiovascular disease and heart bypass surgery one year prior to dental treatment.
\end{abstract}

Key Words: endodontics, cardiovascular diseases, heart bypass surgery, geriatric

\section{INTRODUCTION}

Cardiovascular diseases comprise a group of diseases of the heart and vascular system, affecting the majority of individuals worldwide. ${ }^{1}$ Cardiovascular diseases make up the most prevalent category of systemic disease in Indonesia and many other countries, and its prevalence increases along with age. In Indonesia, coronary heart disease and stroke are estimated to cause more than 470,000 deaths annually. High cardiovascular risk is common among Indonesian adults $\geq 40$ years old. Hypertension, ischemic heart disease, coronary heart disease, and dysrhythmias are some of the cardiovascular conditions that are commonly observed among the population. ${ }^{2}$

Heart bypass surgery or coronary artery bypass surgery is a procedure to replace damaged arteries that supply blood to the heart muscles. The surgery is required when the coronary arteries are blocked or damaged. Blocked arteries restrict blood flow, and it disrupts the heart function. ${ }^{3}$

Treating patients with co-existing cardiovascular disease (heart problem) often raise concern over potential problems during dental treatment. The high prevalence of heart problems in the population makes it the most commonly medically compromised problem seen in dental practices.

Paper presented at the Joint Scientific Meeting in Special Care Dentistry, July 5, 2019, Amerta Room, 4th Floor, main campus of Universitas Airlangga, Surabaya, Indonesia.

Corresponding author: Nanik Zubaidah

Department of Conservative Dentistry

Faculty of Dental Medicine

Universitas Airlangga

J. Mayjen. Prof. Dr. Moestopo No. 47 Surabaya 60132 - Indonesia

Email: nanik-z@fkg.unair.ac.id

The important goal for the patient with cardiovascular disease during dental therapy is to deal with all the identified risk factors involved. Endodontic surgical and non-surgical instrumentation of root canals can produce a transient bacteraemia. It may also occur due to the direct spread of endodontic bacteria into the bloodstream. However, in patients with heart disease, a transient bacteraemia may lead to infective endocarditis and myocardial infection. ${ }^{1}$ 
The purpose of this case report is to describe the comprehensive endodontic management for cardiovascular compromised geriatric patient who has undergone heart bypass surgery.

\section{CASE REPORT}

A 65-year-old woman reported to the Conservative Dentistry and Endodontics Department Dental Hospital of Universitas Airlangga with chief complaints of discomfort and pain on her right mandibular first molar. Her medical record indicated the patient to be suffering from heart disease, and she underwent heart bypass surgery a year ago. The extraoral examination was within normal limits. During the intraoral examination, the right mandibular first molar was found to have secondary caries under composite restoration. The examination resulted in negativity in cold thermal test and K-file test, and positive to percussion and palpation test. Periodontal evaluation showed no abnormality.

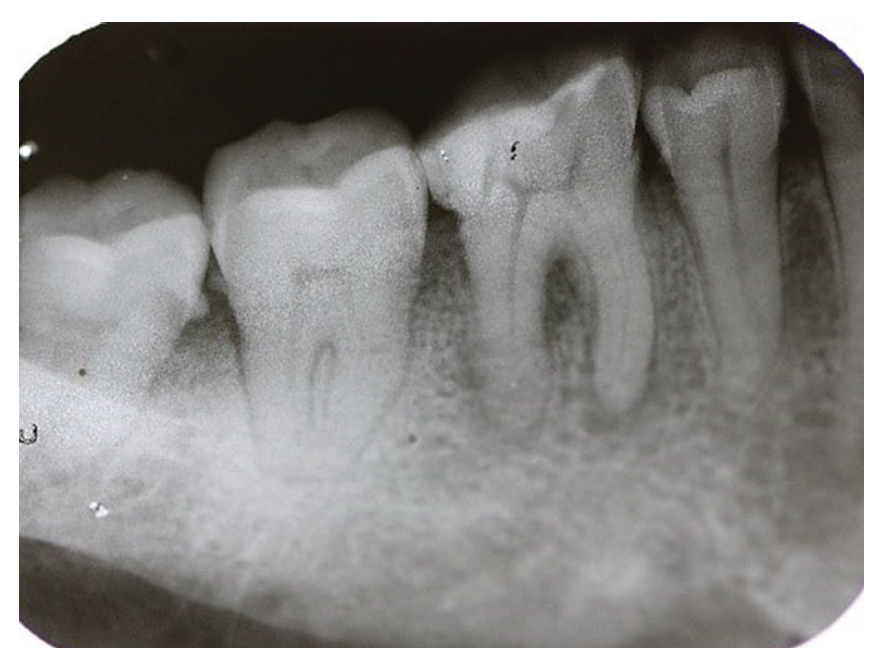

Figure 1. Preoperative intraoral periapical radiograph.
Radiographic examination revealed deep carious lesions under the composite closely approximating the dental pulp with a slight widening of the apical periodontal ligament (Figure 1). A diagnosis of necrotic pulp and symptomatic apical periodontitis was established. Informed consent was obtained.

\section{CASE MANAGEMENT}

After conducting a clinical and radiographic analysis, it was decided that endodontic treatment should be performed. Local anesthesia without adrenaline was administrated, and isolation was achieved through rubber dam (Sanctuary, Dental Dam) placement.

The access cavity was achieved using a round diamond bur and size 2 Endo Access bur (Dentsply Maillefer, Ballaigues, Switzerland). Mesiobuccal, mesiolingual, and distal canals were located (Figure 2A). Refinement of the access cavity was achieved using the Endo $Z$ bur (Dentsply Maillefer, Ballaigues, Switzerland) to have straight access. Three canal orifices were identified with endodontic probes (Osung, DG-16 Double End Endodontic Explorer). Working lengths were determined using an apex locator (Propex Pixi, Dentsply-Maillefer, Ballaigues, Switzerland) with K-files (Dentsply Maillefer, Ballaigues, Switzerland) and confirmed radiographically (Figure 2B, C).

Glide paths were created with K-files up to size \#15 and Proglider (Dentsply Maillefer, Ballaigues, Switzerland). Biomechanical preparation was performed using ProTaper Next Rotary system (Dentsply-Maillefer, Switzerland). A $5.25 \%$ solution of sodium hypochlorite, $17 \%$ ethylenediaminetetraacetic acid, and saline were used alternatively as irrigant at every change of instrument, and final irrigation was performed with $2 \%$ chlorhexidine digluconate. A 30-gauge needle with site vented was used for all irrigants and accompanied by the use of endoactivator (Dentsply-Maillefer, Switzerland). The suggested sequential
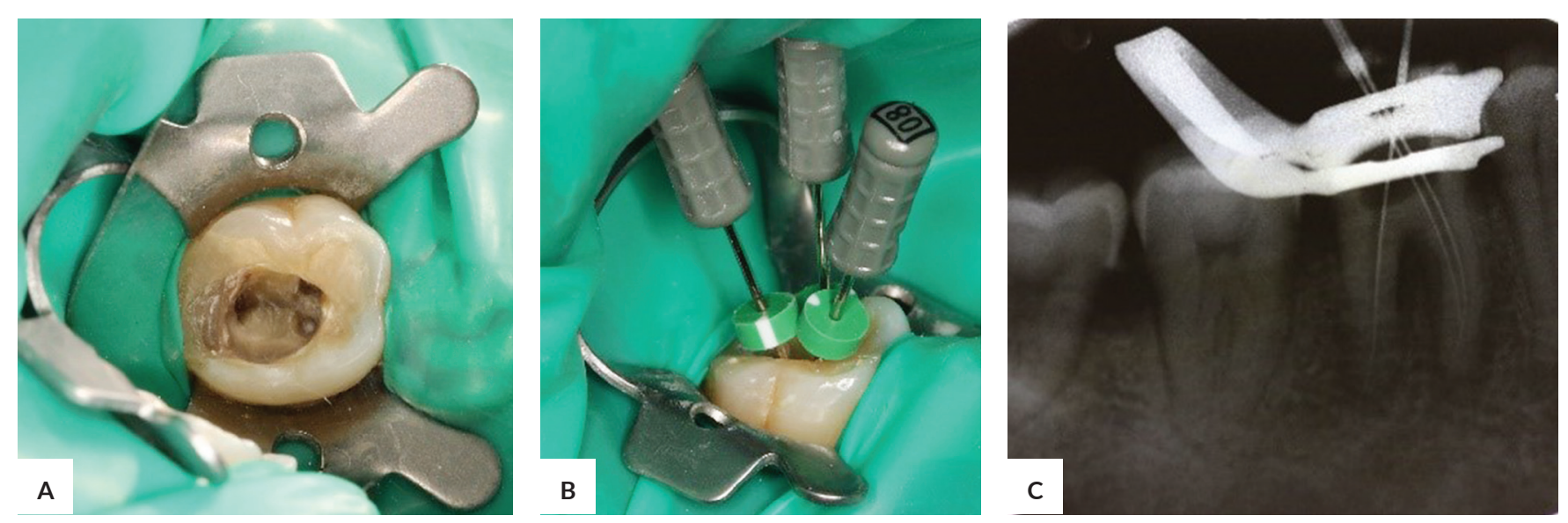

Figure 2. (A) Tooth isolation with a rubber dam and access opening. (B) Determination of working length. (C) Radiographic confirmation of the working length. 

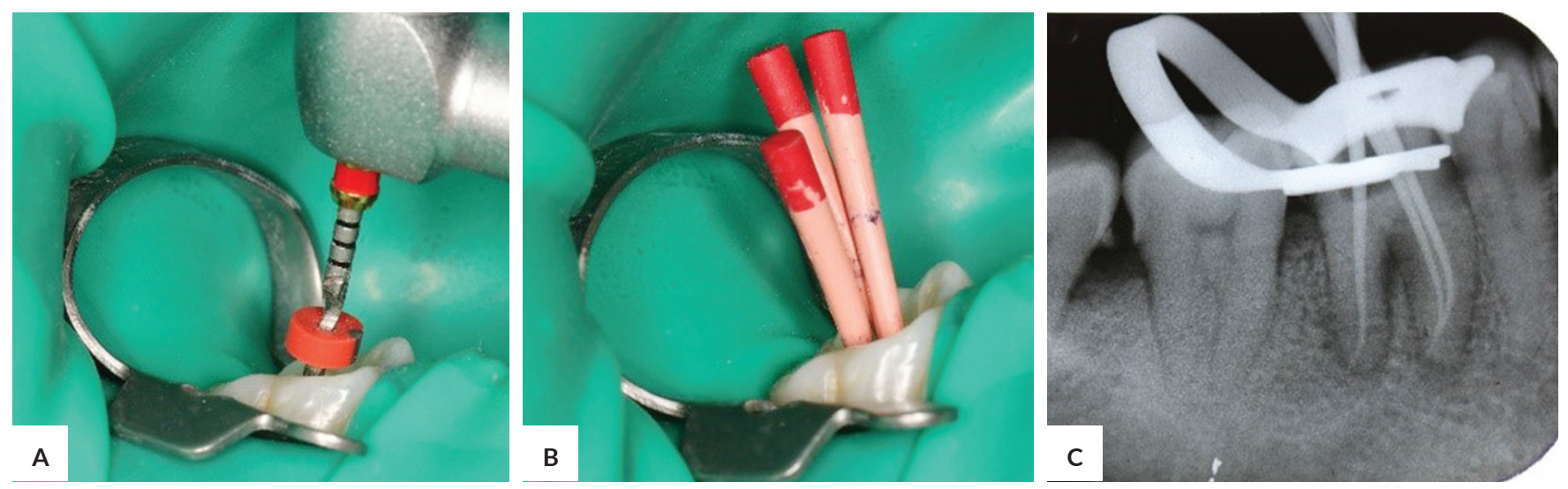

Figure 3. (A) Final preparation with ProTaper Next X2. (B,C) Clinical and Radiographic photograph of trial gutta percha ProTapper Next X2.

method of preparation for ProTaper Next was done in all canals, where all of them were negotiated initially with ProGlider freely in the canal. The ProTaper Next X1 was introduced into the canals, and then with the feather touch brushing motions and preparations were completed till the apex of the canals. After copious irrigation, ProTaper Next $\mathrm{X} 2$ was introduced, and the preparation was completed until the root apex (Figure 3A).

Calcium hydroxide dressing was used as an intracanal medicament for seven days. At the next visit, calcium hydroxide dressing was removed using $\mathrm{K}$-file and under irrigation with sodium hypochlorite and saline and was dried with absorbent paper points. After the main root canals had been cleaned and shaped, trial guttap was performed by gutta-percha ProTaper Next X2 (Figure 3B,C). The single cone obturation was performed using $\mathrm{AH}$ Plus sealer (Dentsply, Maillefer, Ballaigues, Switzerland) (Figure 4A,B).

The permanent restoration was done with the fiber post, and zirconia-based crown and the patient recalled after three months for evaluation (Figure 5A,B). The patient was found to be asymptomatic and satisfied by the esthetic of the zirconia posterior crown (Figure 5C,D).

\section{DISCUSSION}

One of the challenges faced by dental specialists today is in the assessment and management of patients with increasingly complex medical conditions. It is an informationgathering process for assessing the patient's health status, comprises a systematic review of the patient's chief or primary complaint, a detailed history related to this complaint, information about past and present medical conditions, and family histories. ${ }^{4}$ During dental treatment, especially endodontic treatment, the endodontist must know how to deal with healthy and compromised patients and how to complete root canal procedures successfully and without complications.

This reports an endodontic treatment of a 65-yearold and cardiovascular compromised patient. Patient with cardiovascular diseases is more susceptible to physical and emotional stress. Therefore, endodontic treatment should include low-stress protocols and shorter appointments. ${ }^{4}$ The patient may feel tired quickly, anxious, shortness of breath, and unable to open her mouth for a long time. Consequently, single-visit endodontic and long treatment time should not be performed to this patient.
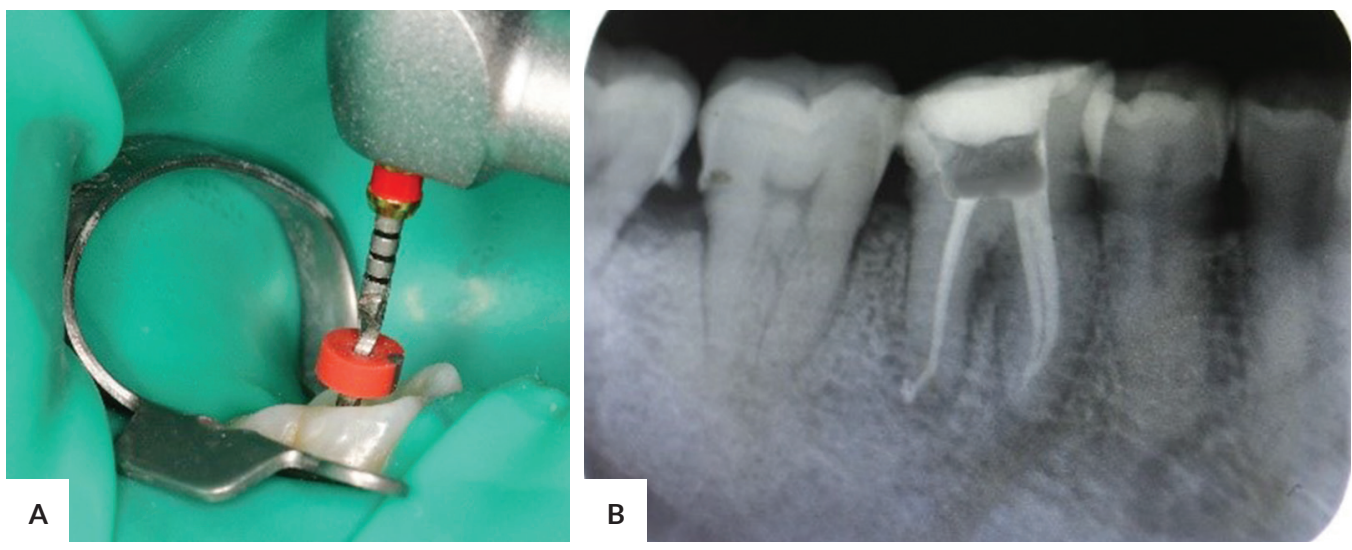

Figure 4. (A) Clinical photograph of final obturation from the occlusal. (B) Radiographic photograph of final obturation. 

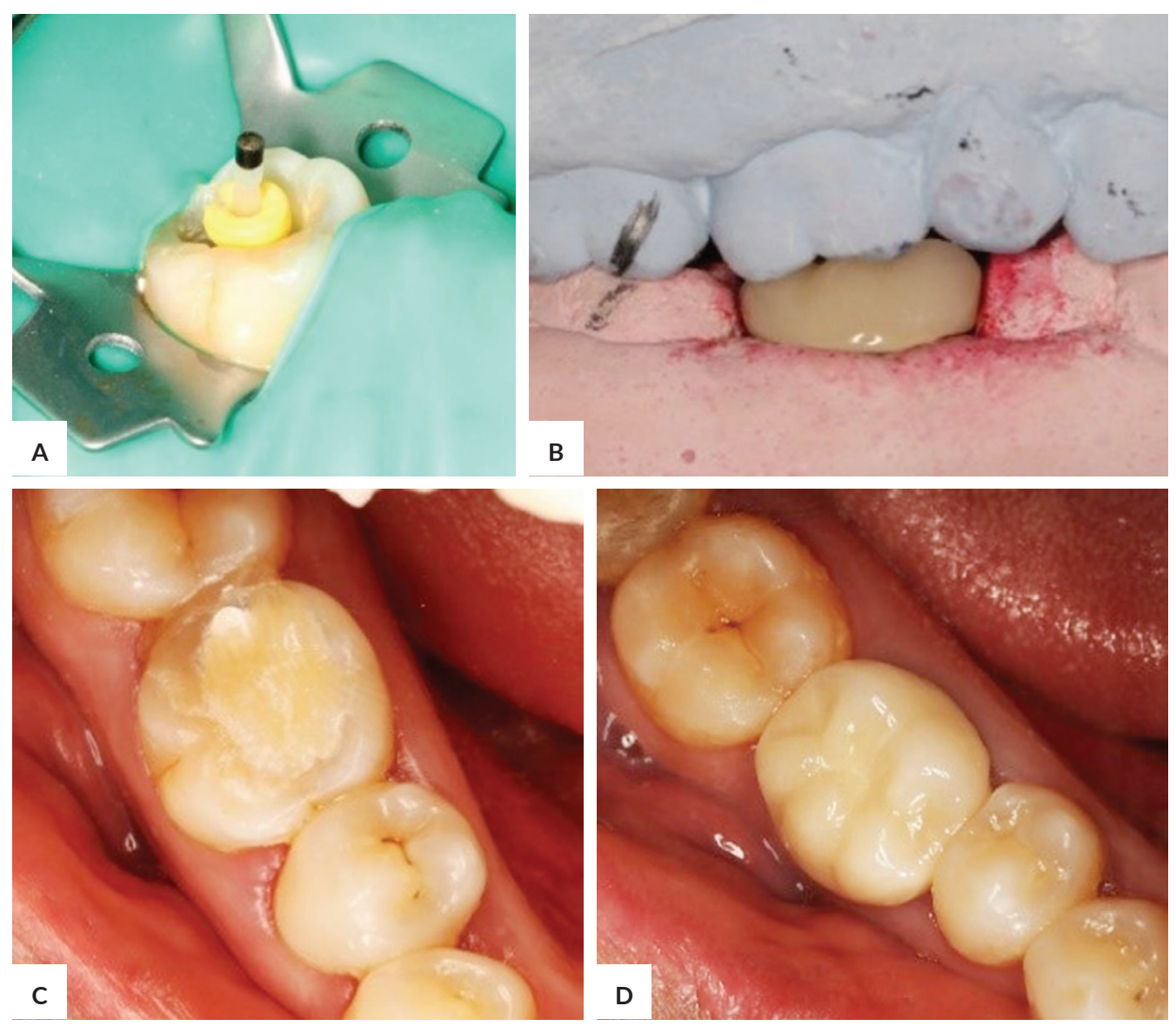

Figure 5. (A) Insertion of fiber post. (B) Zirconia based crown was made. (C) Preoperative intraoral photograph. (D) Postoperative intraoral photograph.

Patient with cardiovascular diseases requires special considerations in relation to endodontic treatment. Not only due to the conditions inherent to the disease, but also the side effects and characteristics of the treatments they receive. Coronary heart disease is very common in the general population, and it is therefore more likely for a dentist to meet with such patient in clinical practice. ${ }^{5}$ Once the dentist discovers that the patient is hypertensive or has other cardiovascular problems, the risk associated with the proposed dental treatment should be weighed with regard to the medical conditions and/or current medications that will demand a modification in the manner in which dental care will be provided. ${ }^{6}$

The primary management goal for the patient with cardiovascular disease during dental therapy is minimizing any hemodynamic alteration during treatment (that is, by maintaining the patient's optimum blood pressure, heart rate, heart rhythm). Psychological and physiological stress during dental treatment has the potential to significantly alter hemodynamic stability. ${ }^{7}$ Dental treatment has the potential to induce stress. The body responds to the stress by the increase of catecholamines (epinephrine and norepinephrine) from the adrenal medulla into the cardiovascular system and can increase the workload on the heart in patients with hypertension or coronary heart disease. ${ }^{8}$ There are some steps that can minimize physical or emotional stress during dental treatment: shorter appointments, preferably in the morning when the patient is well-rested and has a greater physical reserve. ${ }^{9}$ Geriatric patients will also require greater patience and management considerations during endodontic procedures. Patients should be seated comfortably (semisupine) in the dental chair; intermittent rest should be provided to the patient for reducing fatigue; they will have less mobility in and out of the dental chair. The use of a pillow to support the patient's neck will improve patient comfort. ${ }^{10}$ The use of local anesthesia to minimize discomfort, and it should be provided without a vasoconstrictor. A medically compromised patient should not undergo long appointments and excellent postoperative analgesia. ${ }^{6}$ Vasoconstrictors should not be administered to patients with unstable angina, uncontrolled hypertension, or people with recent myocardial infarction and coronary bypass graft. ${ }^{11}$

Biomechanical preparation of ProTaper Next system was used in the treatment. The ProTaper Next rotary instruments have noted advantages such as increased flexibility, higher strength, and wear resistance over the conventional rotary 
endodontic systems. ${ }^{12}$ The use of rotary instrumentation may offer a reduction in number of visits or duration of the working sessions and can offer significant help in many demanding geriatric cases. ${ }^{13}$ The root canal irrigants used in the cleaning phase are divided into those with decalcifying action and those with antibacterial activity. Sodium hypochlorite $(\mathrm{NaOCl})$ is the most widely used irrigant. It dissolves pulp tissue and is a potent anti-microbial agent. Sodium hypochlorite does not remove the smear layer. The combination of $\mathrm{NaOCl}$ and EDTA has been recommended for smear layer removal. Chlorhexidine digluconate has antimicrobial activity but no tissue dissolving capability. ${ }^{14}$

Endodontic treatment and restorative care are essential parts of maintaining the health and well-being of any geriatric patients. In this case report, fiber post and zirconia crown were combined for a durable and restorative treatment. Fiber post has similar physical properties like modulus of elasticity, compressive strength, and flexural strength as dentin. ${ }^{15}$ Zirconia is a great alternative posterior restoration due to high fracture toughness and resistance to wear. ${ }^{16,17}$

\section{CONCLUSION}

A comprehensive multidisciplinary approach while treating medically compromised dental patients is mandatory to reduce complications and to improve the prognosis. The clinician must be mindful of aged patients' emotional and physical needs to ensure proper and comfortable treatment. Today's endodontists are better equipped with applicable knowledge of the systemic disease, and they can deliver highly standardized endodontic treatment and simultaneously minimize the potential problem related to the general health of the patient.

\section{Statement of Authorship}

All authors participated in data collection and analysis, and approved the final version submitted.

\section{Author Disclosure}

All authors declared no conflict of interest.

\section{Funding Source}

None.

\section{REFERENCES}

1. Chaudhry S, Jaiswal R, Sachdeva S. Dental considerations in cardiovascular patients: A practical perspective. Indian Heart J. 2016; 68(4):572-5.

2. Shi A, Tao Z, Wei P, Zhao J. Epidemiological aspects of heart diseases (Review). Exp Ther Med. 2016; 12(3):1645-50.

3. Diodato M, Chedrawy EG. Coronary artery bypass graft surgery: the past, present, and future of myocardial revascularisation. Surg Res Pract. 2014; 2014:726158.

4. Jain P. Common Complication in Endodontics: Prevention and Management, 1st ed. Jain P, ed. Springer; 2018. p. 292.

5. Cruz-Pamplona M, Jimenez-Soriano Y, Sarrion-Perez MG. Dental considerations in patients with heart disease. J Clin Exp Dent. 2011; 3(2):e97-105.

6. Kamath M, Mala K, Thomas MS. Modification of dental care for patients with cardiac disease. Oral Health Dent Manag. 2016; 15(5):286-90.

7. Rose LF, Mealey B, Minsk L, Cohen DW. Oral care for patients with cardiovascular disease and stroke. J Am Dent Assoc. 2002; 133(1):37S-44S.

8. Gordan R, Gwathmey JK, Xie LH. Autonomic and endocrine control of cardiovascular function. World J Cardiol. 2015; 7(4):20-14.

9. Ettinger RL. Treatment planning concepts for the ageing patient. Aust Dent J. 2015; 60 Suppl 1:71-85.

10. Johnstone M, Parashos P. Endodontics and the ageing patient. Aust Dent J. 2015; 60 Suppl 1:20-7.

11. Nadig RR, Usha G, Kumar V, Rao R, Bugalia A. Geriatric restorative care - the need, the demand and the challenges. J Conserv Dent. 2011; 14(3):208-14.

12. Patnana AK, Chugh A. Endodontic management of curved canals with protaper next: A case series. Contemp Clin Dent. 2018; 9(Suppl 1): S168-72.

13. Retsas A, Kalogeropoulos K, Kossioni AE. The use of rotary instruments in endodontic therapy of older dental patients. Stoma Edu J. 2015;2(1):64-9.

14. Haapasalo M, Shen Y, Wang Z, Gao Y. Irrigation in endodontics. Br Dent J. 2014; 216(6):299-303.

15. Lamichhane $\mathrm{A}, \mathrm{Xu} \mathrm{C}$, Zhang FQ. Dental fiber-post resin base material: a review. J Adv Prosthodont. 2014; 6(1):60-5.

16. Daou EE. Esthetic prosthetic restorations: reliability and effects on antagonist dentition. Open Dent J. 2015; 9:473-81.

17. Özkurt-Kayahan Z. Monolithic Zirconia: A review of the literature. Biomed Res. 2016;27(4):1427-36. 